\title{
On Promotion of Innovation Ability of Liquor Enterprises from Perspective of Human Capital
}

\author{
Xiaoli Liu \\ Economics and Management School, Sichuan University of Science and Engineering, Zigong, \\ 643000, China
}

Keywords: Human capital. Liquor enterprise. Innovation ability

\begin{abstract}
Innovation ability is of prime importance for enterprise development. Without innovation ability, development is impossible. It is also the case for development of liquor enterprises. How to improve innovation ability of liquor enterprises from the perspective of human capital has become key links of enterprise development. This paper defines relevant concepts, specifies the tasks of human capital innovation management in modern enterprises, expounds the role of human capital management in improving innovation ability of liquor enterprises and puts forward the countermeasures to promote innovation ability of liquor enterprises from the perspective of human capital.
\end{abstract}

\section{Introduction}

Innovation is an inevitable choice to maintain enterprise survival and development. The improvement of innovation ability is a critical factor to boost core competitiveness of liquor enterprises. The key point of innovation ability lies in applying new thinking to innovate and improve enterprise products and services. After entering the era of knowledge economy, as knowledge and technology improve, human capital of employees in liquor enterprises will certainly promote further improvement of the innovation ability. Enterprise innovation activities cannot be separated from human capital. Human capital and material capital cooperate with each other and interact benignly. Thus, prominent innovation performance will certainly occur. So, discussion of innovation ability of liquor enterprises from the perspective of human capital has important practical significance for studying enterprise innovation ability.

\section{Definition of related concepts}

Human capital mainly refers to knowledge, skill and proficiency of employees which are gained through education, health care, professional training, migration and other human resource investment. In other words, human capital refers to the input in health, knowledge and skills of workers accumulated in the input form of health care, education and migration. Its essence is the sum of various qualified of workers. It reflects scarcity of people's idea, knowledge, skill and health and corresponding relation of market supply and demand.

Enterprise innovation ability mainly refers to the degree of enterprise to comprehensively and systematically relevant various activities and abilities, including the following three aspects: 1) whether the enterprise can technically transform scientific concept to products, produce and provide them for vast consumers; 2) whether the products provided by the enterprise can be accepted by customers and whether the enterprise can effectively persuade customers to accept the products; 3 ) whether the enterprise can effectively manage the process and gain certain financial return.

\section{Tasks of human capital innovation management in modern enterprises}

To meet rapid development requirement of modern enterprises, it is required to implement scientific and effective optimization and improvement of human resources in a planned and organized way. This will be bound to stimulate employees' working enthusiasm, boost enterprise 
production efficiency and economic benefit and drive enterprise soar. Human capital innovation management in modern enterprises has four tasks as follows: 1) to carry out human resource planning and allocation. It is required to apply planning, organization, coordination, recruitment and selection to ensure to provide enterprises with management personnel, technical personnel and common workers with enough quantity and quality so as to satisfy the demand of modern enterprise development for personnel. 2) To assist employees to plan their career. In human capital management innovation of modern enterprises, it is necessary to help employees to plan practical career objectives through selecting, appointing and assessing employees and try to help employees to reach their objectives so as to promote their rapid growth. 3) To excavate employees' potential ability more deeply. In the process of human capital innovation management, education, training and special lecture can be adopted to continuously improve employees' labor capacity and professional quality, better excavate employees' internal potential and increase the accumulation of human capital so as to realize good harvest of economic benefit and social benefit. 4) To put enterprise performance evaluation and incentive mechanism into practice. Enterprises should apply work analysis results to formulate strict and efficient job specification and procedure as important basis of performance evaluation and stimulate employees' enthusiasm and creativity through rational reward, welfare and promotion according to the evaluation results.

\section{Role of human capital management in improving innovation ability of liquor enterprises}

To survive and develop in increasingly fierce liquor market competitions, liquor enterprises should continuously seek new opportunities in the market and deeply excavate their internal resources to form more unique core competitiveness. Core competitiveness of liquor enterprises is mainly reflected in formative knowledge, ability, information, resources and values etc. But, not all knowledge and skills of liquor enterprises can form core competitiveness. Only when they own value, inimitability and irreplaceability simultaneously can they really form enterprise core competitiveness. Meanwhile, human capital owns the feature of core competitiveness.

Firstly, the value of human capital can achieve core value customers pay attention to so as to save cost and improve economic benefit. The value of human capital is mainly reflected in applying rational and effective human resource management activities so as to reduce enterprise cost, increase economic benefit and create more valuable products. The quality and quantity of human capital owned by liquor enterprises are the source of enterprise competitiveness. Enterprise competitive advantage including liquor enterprises is mainly reflected in the minority of excellent human capital. Enterprises should provide employees with good work environment and hardware facilities suitable for their growth and development. Employees should constantly strive to improve the stock of human capital.

Secondly, the scarcity of human capital can improve product peculiarity. No matter how advantageous the conditions are, human capital of a person and the duration are quite limited. The formation of human capital and continuous rise in the stock need constant input in scare resources such as labor, time and money. For different enterprises, the opportunities for gaining scare resources are unequal. But, about the question who can gain these resources, different enterprises have no natural inequality. Unequal knowledge and capacity of different enterprises lead to the difference in resource acquisition and capacity decision-making. Thus, liquor enterprises can win the initiative in liquor market full of fierce competitions only through continuously innovating. People serve as the sole factor which can generate innovation effect in economic activities. Uniqueness of a kind of liquor mainly depends on innovation ability of employees producing and developing such liquor. Different enterprises have different product peculiarity due to different conditions of innovation human capital. Besides, even if employees own creative ideas, excellent job performance often owes to initiative spirit resulted from effective human resource management of liquor enterprises. Thus, liquor enterprises can really form competitiveness advantage only through identifying and developing scarcity of human capital so as to help enterprises gain new profit growth. 
Thirdly, inimitability of human capital is important foundation of liquor enterprises to gain long-term competitive edge. It is hard for liquor enterprises to continue to maintain large quantities of strategies used to gain a competitive edge. This is because it can be easily imitated by other enterprises. However, unique development course, it is difficulty for competitors to imitate cultural atmosphere and peculiar ability owned by an enterprise. Therefore, the competitive edge which is difficult to imitate and owned through human capital is more lasting than the competitive edge owned by use of other means. The investment in human capital can allow employees to develop and apply enterprise resource allocation more effectively so that the enterprise can keep multiple links (including production, operation and management) harmonious and uniform and then form irreplaceable unique advantages and long-term competitive edge.

\section{Countermeasures to improve innovation ability of liquor enterprises from the perspective of human capital}

\section{To enhance development force for innovative human capital}

Human capital innovation management possesses scarce innovation ability in the society. So, it is required to enhance human capital innovation and development force, continuously improve and optimize human capital allocation. Liquor enterprises can start from human capital recruitment and rationally improve entry threshold of this industry. High requirements should be formulated for project managers. They should at least own the idea of overall situation and strong organizing ability. Innovation managers of liquor enterprises should own rich knowledge and technical capacity. Innovation managers of liquor enterprises should deal with post arrangement and rational allocation of tasks during application of personnel. Every employee should be matched with his post. Besides, the ability of every employee should be exerted to the largest extent. It is required to realize maximization of the efficiency of human capital. It is required to apply value chain management according to market competition demand of liquor market, arrange employees in the proper posts, reinforce appointment and work shift for innovation talents and update their knowledge so as to realize optimal allocation of human capital, continuous improvement of core competitiveness and creation of larger values.

\section{To price human capital according to marketization principle}

Human capital value of liquor enterprises mainly includes exchange value and surplus value. The former mainly refers to employees' working capacity and technical value, specifically reflected in employee wage, bonus and welfare. The former mainly includes economic benefit and potential benefit created by employees. Human capital pricing of liquor enterprises is am major manifestation pattern of market allocation of human capital. Under socialist market economy with Chinese characteristics, human capital pricing of liquor enterprises must strictly abide by marketization operation principle and continuously establish marketization adjustment system for human capital pricing, i.e. regulate and control human capital pricing of liquor enterprises in accordance with practical supply and demand as well as competition system of human capital market.

\section{To increase investment in human capital innovation ability}

To further accelerate accumulation and appreciation of human capital in liquor enterprises, the investment in human capital innovation ability must be increased. Liquor enterprises should increase capital input, apply flexible training forms, lower training cost and continuously improve training efficiency. Liquor enterprises should rationally utilize training funds and training subsidies provided by the government and apply training incentive to carry out various forms of training at multi-level so as to boost the efficiency of human capital innovation ability. Besides, orientation training and further education training should be implemented in a planned and organized manner. The training and education for human capital at each level of liquor enterprises should be carried out in order to gain human capital, provide sufficient further education and training opportunities and better realize self-value. Liquor enterprises should stick to people-oriented principle to cultivate innovation personnel with high analysis and decision-making ability, high foreign language level and proficiency in computer operation so as to build high-quality management and innovation teams. 


\section{To practically help employees plan their career}

Under current economic system, liquor enterprises should require employees continuously enhancing learning, fully updating knowledge reserve and exploring new technology so as to promote continuous improvement and development of employees. Of course, self-development desire of liquor enterprise employees is not limited to meeting current post and the work. Their objectives should be to lay good foundation for their future vocational development and create better conditions. Liquor enterprises should assist employees in planning their career, support and encourage employees' self-development desire. In this way, the deviations of enterprises and employees in objective integration process can be controlled more effectively. Besides, the deficiency in subjective initiative can be avoided. For human capital innovation management of liquor enterprises, systematized training and education for employees should be implemented so as to provide good opportunities for improving individual skills. In this way, they will own the ability of lifetime employment.

\section{Conclusions}

In conclusion, innovation ability of human capital management plays a very important role in liquor enterprises and also has large development potential. Liquor enterprises should comprehensively set up people-oriented idea and establish management mechanism based on innovation personnel development and devoted to realizing sustainable development. It is required to perfect and improve human capital incentive system in line with the requirements of improving entrepreneurial ability of liquor enterprises so as to driver improvement of human capital innovation ability.

\section{Acknowledgments}

This paper is the planned project of Sichuan philosophy and social science research "On innovation ability of Sichuan liquor industrial cluster based on human capital perspective" (project No.: SC13E036); the project of research center for Sichuan liquor development "Study on human resource development of Sichuan liquor enterprises based on cultivation of independent innovation capability" (project No.: CJYB10-14); the planned project of Zigong philosophy and social science research "Research of enterprise innovation ability in Zigong".

\section{References}

[1] Liu Yewen: Study on innovation human capital management in modern enterprises, Hunan Normal University Press, 2008

[2] Sun Bing: Grief of management - maximization of human capital, Tianjin: Nankai University Press, 2009

[3] Yan Peng: Study on enterprise innovation ability, Productivity Research, 2007 (19)

[4] He Min: Innovation research of human capital on Chinese enterprise management, Guide to Business, 2009 (9)

[5] He Feiye: He Weisheng, Research of effects of human capital on innovation ability of small and medium-sized technology-based enterprises, Oriental Enterprise Culture, 2011 (7) 